\title{
Structure of Iron-Carbon Martensite in the Transition State from the First to the Third Stage of Tempering Studied by Electron Microscopy and Diffraction
}

\author{
By Yoshio Nakamura* and Sigemaro Nagakura*†
}

\begin{abstract}
The structure of 1.5 mass $\% \mathrm{C}$ martensite tempered at $470 \mathrm{~K}$ for $180 \mathrm{ks}$ has been investigated. In the matrix $\alpha$-iron, $\eta$ - $\mathrm{Fe}_{2} \mathrm{C}$ and $\theta^{\prime}$-particles coexist. The $\eta$ - $\mathrm{Fe}_{2} \mathrm{C}$ particle is the precipitate at the first stage, while the $\theta^{\prime}$-particle is the precipitate at the early third stage and made of thin layers of $\theta-\mathrm{Fe}_{3} \mathrm{C}$ and $\chi$ $\mathrm{Fe}_{5} \mathrm{C}_{2}$ grown microsyntactically. At the transition from the first to the third stage, the $\theta^{\prime}$-particle nucleates on the surface of the $\eta-\mathrm{Fe}_{2} \mathrm{C}$ particle and then grows at the expense of carbon in the matrix. The $\eta$ - $\mathrm{Fe}_{2} \mathrm{C}$ particle disappears after the $\theta^{\prime}$-particle has grown sufficiently large. The carbides making the $\theta^{\prime}$-particle have slightly larger lattice parameters than the ideal values. Owing to this good coherency is kept with the matrix. When the $\theta-\mathrm{Fe}_{3} \mathrm{C}$ particle appears at the later third stage, it has the ideal lattice parameters, but the coherency with the matrix is not so good as the $\theta^{\prime}$-particle. Since the $\theta^{\prime}$-particle and the $\theta$-particle are different in nature from each other, they should be distinguished in discussing the martensite tempering.
\end{abstract}

(Received July 17, 1986)

Keywords: iron-carbon martensite, tempering, transition state, the third stage, $\theta^{\prime}$-particle, microsyntactic intergrowth, $\theta-\mathrm{Fe}_{3} \mathrm{C}, \chi-\mathrm{Fe}_{5} \mathrm{C}_{2}$, nucleation and growth, lattice parameter anomaly, high resolution electron microscopy

\section{Introduction}

It has been well established that at the first stage of tempering of iron-carbon martensite $(370-420 \mathrm{~K})$ the precipitates are $\eta-\mathrm{Fe}_{2} \mathrm{C}$ (orthorhombic, Pnnm, $a=0.471, b=0.433$ and $c=0.287 \mathrm{~nm}$ ) and the matrix is the low carbon martensite $\alpha^{\prime \prime}$ (axial ratio $c / \mathrm{a}=1.005-$ $1.010)^{(1)-(6)}$. On the other hand, recent electron microscopic studies ${ }^{(7)(8)}$ have shown that at the early third stage $(500-720 \mathrm{~K})$ the precipitates are not $\theta-\mathrm{Fe}_{3} \mathrm{C}\left(\theta\right.$-particle) but $\theta^{\prime}$-particles ${ }^{(9)}$, in which thin layers of $\theta-\mathrm{Fe}_{3} \mathrm{C}, \chi-\mathrm{Fe}_{5} \mathrm{C}_{2}$ and rarely higher carbides $\theta_{n}-\mathrm{Fe}_{2 n+1} \mathrm{C}_{n} \quad(n \geqq 3)^{(7)}$ grow microsyntactically. The $\theta$-particle appears only at the later third stage of tempering above about $770 \mathrm{~K}$. Throughout the third stage the matrix is $\alpha$-iron. However, the mechanism of structure transition from the first to the third stage has never been established. The present

* Department of Metallurgy, Tokyo Institute of Technology, Meguro-ku, Tokyo 152, Japan.

+ Present address: Technological University of Nagaoka, Nagaoka 940-21, Japan. study was made in order to solve this problem. It was found that the $\theta^{\prime}$-particle nucleates on the surface of $\eta-\mathrm{Fe}_{2} \mathrm{C}$ particle and grows. Also found was an anomaly in the lattice parameters of carbides composing the $\theta^{\prime}$-particle. These are described in this paper.

\section{Experimental}

Zone refined iron rods (99.99\% pure) were cold-rolled to plates with thickness of $0.1 \mathrm{~mm}$ and carburized with a methane-hydrogen mixed gas at $1220 \mathrm{~K}$ for $3.6 \mathrm{ks}$. The carburized plates were austenitized at $1320 \mathrm{~K}$ for $1.2 \mathrm{ks}$ and subjected to quenching into water kept at $293 \mathrm{~K}$, followed by immersion in liquid nitrogen. Martensitic plates of 1.5 mass $\% \mathrm{C}$ were obtained. The carbon content was determined from the axial ratio of martensite lattice.

The produced martensite plates were sealed in evacuated capsules and tempered at $470 \mathrm{~K}$ for $180 \mathrm{ks}$. The tempered plates were electrolytically thinned using a $\mathrm{H}_{3} \mathrm{PO}_{4}-\mathrm{CrO}_{3}$ electrolyte kept at $340 \mathrm{~K}$ for electron microscopic observations. A JEM-200CX electron 
microscope operated at $200 \mathrm{kV}$ was used for observations.

The axial ratio of the matrix after the tempering was unity within the experimental error, indicating that the carbon content in the matrix is less than that of the low carbon martensite $\alpha^{\prime \prime}$. Accordingly, we use the notation $\alpha$ to represent the matrix phase.

\section{Results}

\section{Structure in the transition state from the first to the third stage}

Figure 1(a) shows an electron diffraction pattern of a tempered 1.5 mass $\% \mathrm{C}$ martensite at $470 \mathrm{~K}$ for $180 \mathrm{ks}$. The incident beam direction is $[0 \overline{1} \overline{1}]_{\alpha}$. The strong spots are due to the matrix $\alpha$ and the medium strong spots due to $\eta-\mathrm{Fe}_{2} \mathrm{C}$. The orientation relationships between $\eta$ - $\mathrm{Fe}_{2} \mathrm{C}$ and $\alpha$-iron are $(100)_{\eta} / /(01 \overline{1})_{\alpha}$ and $(001)_{\eta} / /(100)_{\alpha}$ in accordance with previous studies $^{(1)-(6)(8)(10)}$. Besides these spots, diffuse weak spots due to the double diffraction between $\eta$ and $\alpha$ (indicated by arrowheads), and sharp weak spots due to the $\theta^{\prime}$-particle (indicated by arrows) are observed. Figure $1(\mathrm{~b})$ is a dark field electron micrograph taken with the spots in the encircled area around the $\overline{1} 01_{\eta}$ spot in Fig. 1(a). The $\eta-\mathrm{Fe}_{2} \mathrm{C}$ particles give fine spotty images with size of about $5 \mathrm{~nm}$, in which moiré fringes due to the double diffraction between $01 \overline{1}_{\alpha}$ and $200_{\eta}$ run in parallel with $\langle 100\rangle_{\alpha}$ with spacing of about $1.5 \mathrm{~nm}$, and they line up along about the $[100]_{\alpha}$ direction. This arrangement gives a rod-like image to $\eta$ - $\mathrm{Fe}_{2} \mathrm{C}$ particle in a low magnified micrograph. At the center of the figure, an image as large as $80 \times 30 \mathrm{~nm}^{2}$ is observed. This is the image of $\theta^{\prime}$ particle. The stripes in the particle show the microsyntactic intergrowth of carbide layers.

Figure 2 reproduces a lattice image of the $\theta^{\prime}$ particle shown in Fig. 1(b). This image was obtained using the reflections in the encircld area in the attached diffraction pattern, and the reproduced area corresponds to the area indicated by the arrow in Fig. 1(b). The layers of wider fringe spacing $(B, D$, etc.) were identified with $\theta-\mathrm{Fe}_{3} \mathrm{C}$, and those of narrower fringe spacing ( $\mathrm{A}, \mathrm{C}$, etc.) with $\chi-\mathrm{Fe}_{5} \mathrm{C}_{2}$. The moiré fringes observed in the upper part show the coexistence of $\eta$ - $\mathrm{Fe}_{2} \mathrm{C}$ particles with the $\theta^{\prime}$-particle.

The following facts have been obtained from the observations:

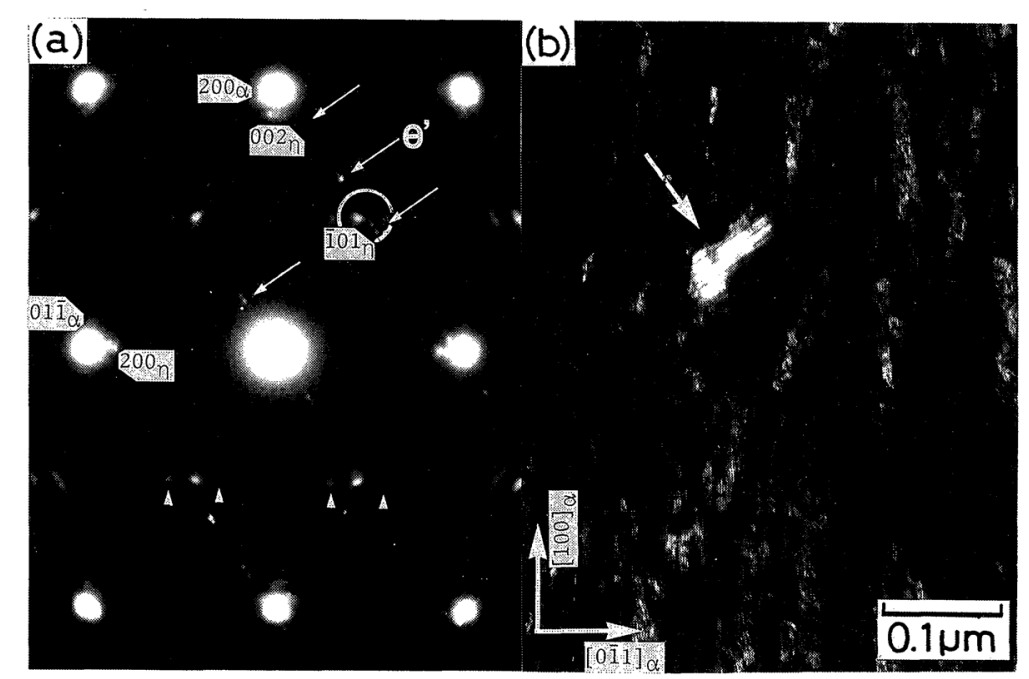

Fig. 1 (a) Electron diffraction pattern obtained from a 1.5 mass $\% \mathrm{C}$ martensite foil tempered at $470 \mathrm{~K}$ for $180 \mathrm{ks}(50 \mathrm{~h})$. Strong spots are due to $\alpha$-iron and medium to $\eta-\mathrm{Fe}_{2} \mathrm{C}$. The spots indicated by arrowhead are due to double diffraction between $\alpha$-iron and $\eta-\mathrm{Fe}_{2} \mathrm{C}$ and those by arrows due to $\theta^{\prime}$-particle. Beam incidence is along the $[0 \overline{1} \overline{1}]_{\alpha}$ and $[0 \overline{1} 0]_{\eta}$ directions. (b) Dark field image taken with spots in the encircled area around the $\overline{1} 01_{\eta}$ spot in (a). The particle indicated by an arrow is a $\theta^{\prime}$-particle and the others are $\eta-\mathrm{Fe}_{2} \mathrm{C}$ particles. 


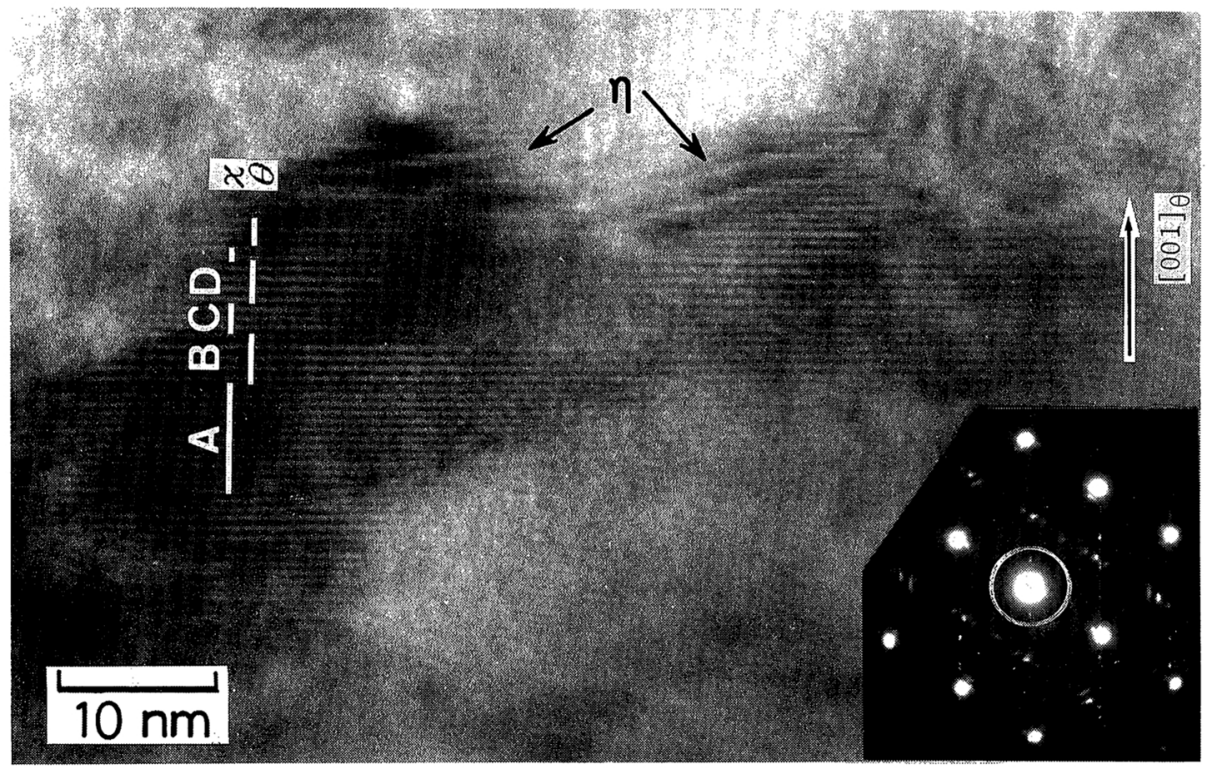

Fig. 2 High resolution lattice image of the $\theta^{\prime}$-particle shown in Fig. 1(b). A and $\mathrm{C}$ are the $\chi-\mathrm{Fe}_{5} \mathrm{C}_{2}$ layers, and $\mathrm{B}$ and $\mathrm{D}$ the $\theta-\mathrm{Fe}_{3} \mathrm{C}$ layers. Moiré fringes produced by the overlapping of $\alpha$-iron and $\eta-\mathrm{Fe}_{2} \mathrm{C}$ are observed at the edge of the $\theta^{\prime}$-particle.

(1) The $\theta^{\prime}$-particles coexist with $\eta$-Fe ${ }_{2} \mathrm{C}$ par- equal. ticles.

(2) Particles composed only of $\theta-\mathrm{Fe}_{3} \mathrm{C}$ or $\chi-\mathrm{Fe}_{5} \mathrm{C}_{2}$ are never formed.

(3) In the $\theta^{\prime}$-particle, the layer thickness of $\theta-\mathrm{Fe}_{3} \mathrm{C}$ and $\chi-\mathrm{Fe}_{5} \mathrm{C}_{2}$ are $3-6 \mathrm{~nm}$, and the amounts of the respective carbides are almost

\section{Lattice parameters of $\theta-\mathrm{Fe}_{3} \mathrm{C}$ and $\chi$ - $\mathrm{Fe}_{5} \mathrm{C}_{2}$ in the $\boldsymbol{\theta}^{\prime}$-particles}

Figure 3(a) is a lattice image and (b) the corresponding diffraction pattern, taken with the beam incidence along $[0 \overline{1} \overline{1}]_{\alpha}$. In (a), the region

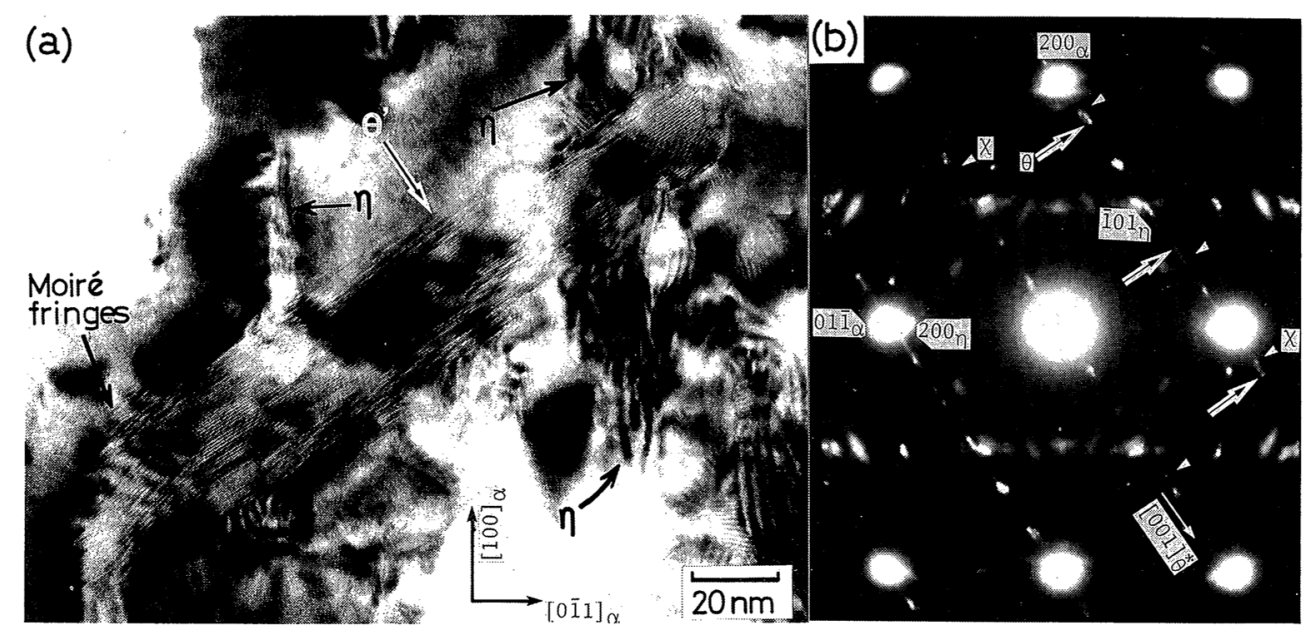

Fig. 3 (a) High resolution lattice image of a $\theta^{\prime}$-particle. Zigzag moiré fringes due to the overlapping of two $\theta^{\prime}$-particles are observed at the lower left of the $\theta^{\prime}$-particle. (b) Electron diffraction pattern corresonding to (a). Arrows indicate the spots due to $\theta-\mathrm{Fe}_{3} \mathrm{C}$, and arrowheads $\chi-\mathrm{Fe}_{5} \mathrm{C}_{2}$. Beam incidence is along $[0 \overline{1} \overline{1}]_{\alpha} / /[0 \overline{1} 0]_{\eta} / /[\overline{1} 00]_{\theta} / /[010]_{\chi}$. 
of fine fringes is a $\theta^{\prime}$-particle, and the regions of wider moiré fringes are overlapped regions of $\eta-\mathrm{Fe}_{2} \mathrm{C}$ and ferrite $\alpha$. At the lower left of the image zigzag moiré fringes are seen, which are formed by the overlapping of two $\theta^{\prime}$-particles. In (b), some of the spots due to $\theta-\mathrm{Fe}_{3} \mathrm{C}$ and some due to $\chi-\mathrm{Fe}_{5} \mathrm{C}_{2}$ are indicated by arrows and arrowheads, respectively. The orientation relationships among $\theta-\mathrm{Fe}_{3} \mathrm{C}, \chi-\mathrm{Fe}_{5} \mathrm{C}_{2}$ in the $\theta^{\prime}$ particle and matrix $\alpha$ are as follows. $(100)_{\theta} / /$ $(0 \overline{1} 0)_{\chi} / /(011)_{\alpha}, \quad(001)_{\theta} / /(100)_{\chi} / /(\overline{2} \overline{1} 1)_{\alpha} \quad$ and $[010]_{\theta} / /[001]_{\chi} / /[\overline{1} 1 \overline{1}]_{\alpha}$. The orientaion relationship between $\theta-\mathrm{Fe}_{3} \mathrm{C}$ and matrix $\alpha$ is Bagaryatskiy's ${ }^{(11)}$, and that between $\chi-\mathrm{Fe}_{5} \mathrm{C}_{2}$ and $\alpha$-iron is one of the orientation relationships made from Bagaryatskiy's and the relation between $\theta-\mathrm{Fe}_{3} \mathrm{C}$ and $\chi-\mathrm{Fe}_{5} \mathrm{C}_{2}$ i.e. $(001)_{\theta} / /(100)_{\chi},(100)_{\theta} / /$ $(010)_{\chi}$ and $[010]_{\theta} / /[001]_{\chi}^{(7)}$.

Assuming the lattice parameter of the martix $\alpha$ to be $0.2866 \mathrm{~nm}$, the lattice parameters of $\theta$ $\mathrm{Fe}_{3} \mathrm{C}$ and $\chi-\mathrm{Fe}_{5} \mathrm{C}_{2}$ in the $\theta^{\prime}$-particles were measured. The results are shown in Table 1 and compared with their ideal values ${ }^{(12)(13)}$. For $\theta-\mathrm{Fe}_{3} \mathrm{C}$, the observed $b$ and $c$ values are 1.4 and $3.5 \%$ larger than the ideal values, respectively, although $a$ values are almost equal. This results in that the observed axial ratio $c / b$ is 2.0\% larger than the ideal axial ratio 1.325 . Such a lattice parameter anomaly exists in all

Table 1 Lattice parameters of $\theta-\mathrm{Fe}_{3} \mathrm{C}$ and $\chi-\mathrm{Fe}_{5} \mathrm{C}_{2}$ in $\theta^{\prime}-$ particles.

(1) $\theta-\mathrm{Fe}_{3} \mathrm{C}$ in $\theta^{\prime}$-particles (tempered at $470 \mathrm{~K}$ )

\begin{tabular}{lclc}
\hline \hline & Observed value & Ideal value & Difference \\
\hline$a$ & $0.450 \mathrm{~nm}$ & $0.4525 \mathrm{~nm}$ & $-0.5 \%$ \\
$b$ & 0.516 & 0.5090 & 1.4 \\
$c$ & 0.698 & 0.6744 & 3.5 \\
\hline$c / b$ & 1.35 & 1.325 & 2.0 \\
\hline \hline
\end{tabular}

Observed axial ratio (tempered at $510 \mathrm{~K}$ ) $c / b=1.348 \pm 0.009$

Observed axial ratio in $\theta$-particles (tempered at $870 \mathrm{~K}$ ) $c / b=1.321 \pm 0.002$

(2) $\chi-\mathrm{Fe}_{5} \mathrm{C}_{2}$ in $\theta^{\prime}$-particles (tempered at $470 \mathrm{~K}$ )

\begin{tabular}{lclc}
\hline \hline & Observed value & Ideal value & Difference \\
\hline$a$ & $1.17 \mathrm{~nm}$ & $1.156 \mathrm{~nm}$ & $1.5 \%$ \\
$b$ & - & 4.573 & - \\
$c$ & 0.510 & 0.5060 & 0.8 \\
$\beta$ & $98^{\circ}$ & $97.74^{\circ}$ & 0.3 \\
\hline \hline
\end{tabular}

the $\theta^{\prime}$-particles irrespective of the tempering temperature, as shown in the table. In contrast to this, for the $\theta$-particles in specimens tempered at $870 \mathrm{~K}$, the observed axial ratios $c / b$ are almost equal to the ideal ratio, indicating the absence of lattice parameter anomaly. For $\chi-\mathrm{Fe}_{5} \mathrm{C}_{2}$, the $a$ value is $1.5 \%$ larger than the ideal value and the $c$ value $0.8 \%$. The axial angle $\beta$ is almost the same.

\section{Nucleation site of $\boldsymbol{\theta}^{\prime}$-particle}

In Fig. 3(a), the $\theta^{\prime}$-particle is seen to be formed in contact with the $\eta$ - $\mathrm{Fe}_{2} \mathrm{C}$ particle. In order to confirm this, observations were made along the $[\overline{1} 1 \overline{1}]_{\alpha} / /[011]_{\eta} / /[010]_{\theta}$ direction, which was perpendicular to the observation direction of Fig. 3(a). Figure 4(a) is a dark field image taken with the reflections due to $\theta^{\prime}$-particles in the diffraction pattern of Fig. 4(b). In the fringed images of $\theta^{\prime}$ - particles, a dark region due to $\eta-\mathrm{Fe}_{2} \mathrm{C}$ particle is seen as indicated by the arrow. Figure 4(c) is a bright field image corresponding to the central region of Fig. 4(a). The region of moiré fringes is the $\eta-\mathrm{Fe}_{2} \mathrm{C}$ particle, and it is surrounded by the two $\theta^{\prime}$-particles, as schematically illustrated in Fig. 4(d).

Irrespective of the observation directions, the $\theta^{\prime}$ - and $\eta$-particles were observed to be formed in contact with each other. Therefore, it is reasonable to assume that the $\theta^{\prime}$-particle nucleates on the surface of $\eta-\mathrm{Fe}_{2} \mathrm{C}$ particle and grows. The observed results deny the in situ transformation mechanism from $\eta$ - $\mathrm{Fe}_{2} \mathrm{C}$ particle to $\theta^{\prime}$-particle ${ }^{(14)}$. In fact, the $\eta-\mathrm{Fe}_{2} \mathrm{C}$ particle is fairly stable and can coexist with the $\theta^{\prime}$-particle up to about $520 \mathrm{~K}$. Some authers assumed that the internal twin boundaries in martensite act as the nucleation sites of $\chi-\mathrm{Fe}_{5} \mathrm{C}_{2}{ }^{(15)(16)}$. The present study showed that this nucleation mechanism could not be applied always. In fact, the $\theta^{\prime}$-particle nucleates independent of the internal twin boundary.

\section{Discussion}

Based on the observations, we present the nucleation and growth mechanism of $\theta^{\prime}$-particle as illustrated in Fig. 5(a) and (b), which are viewed respectively along the $[0 \overline{1} \overline{1}]_{\alpha}$ and $[\overline{1} 1 \overline{1}]_{\alpha}$ 


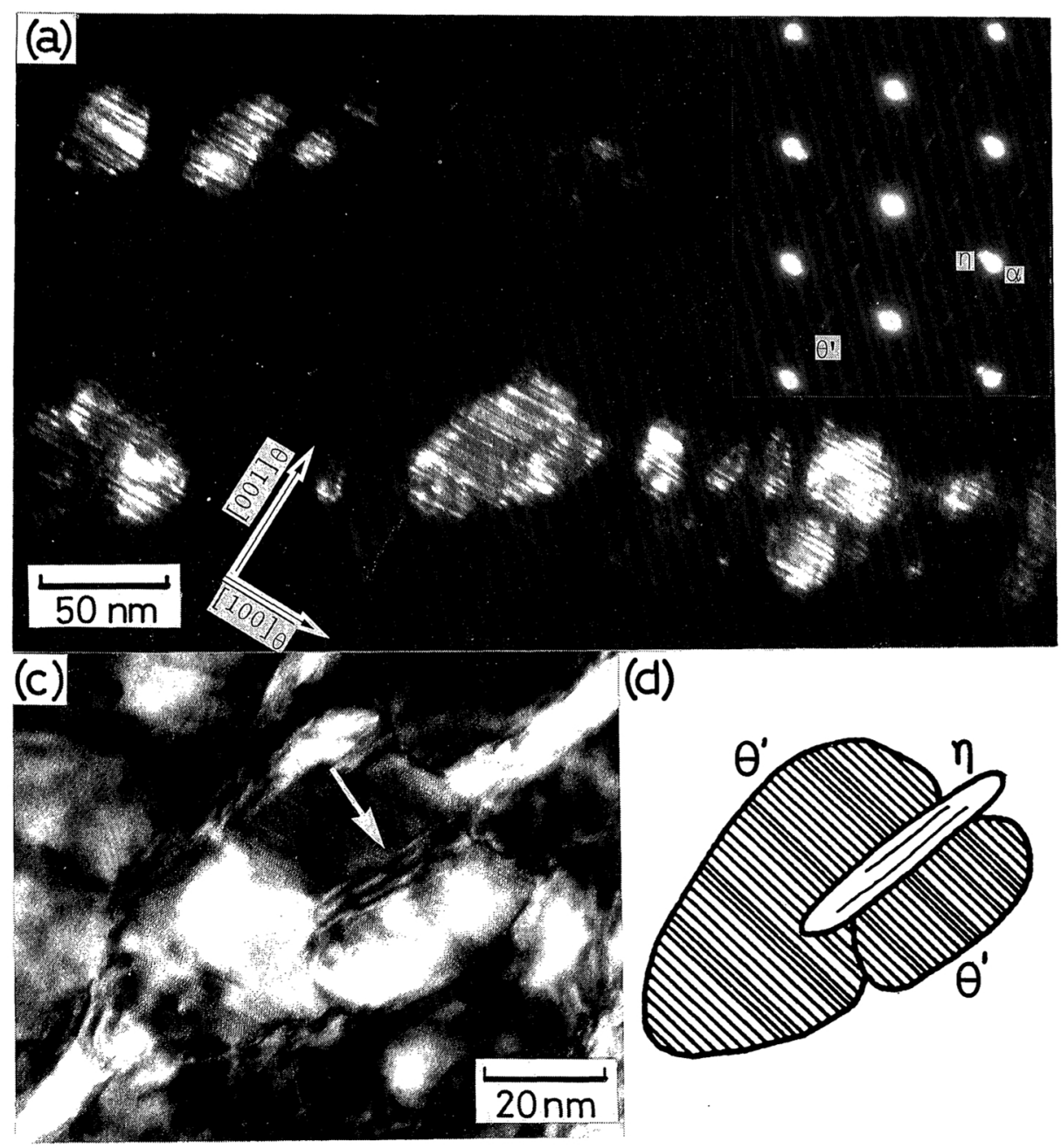

Fig. $4 \theta^{\prime}$-particles precipitated on the interface between $\alpha$-iron and $\eta$-Fe $e_{2} \mathrm{C}$. Beam incidence is along $[\overline{1} 1 \overline{1}]_{\alpha} / /[011]_{\eta} / /[010]_{\theta}$. (a) Dark field image of $\theta^{\prime}$-particles. (b) Electron diffraction pattern corresponding to (a). (c) Bright field image of the $\theta^{\prime}$-particle at the center of (a). Arrow indicates the $\eta$ - $\mathrm{Fe}_{2} \mathrm{C}$ particle. (d) Schematic illustration of the particles in (c).

directions. At first, the $\theta^{\prime}$-particle nucleates on the surface of $\eta-\mathrm{Fe}_{2} \mathrm{C}$ particle and then grows at the expense of carbon atoms in the matrix. When the carbon concentration in the matrix becomes sufficiently low, the $\eta-\mathrm{Fe}_{2} \mathrm{C}$ particle decomposes to liberate carbon and contributes to the further growth of $\theta^{\prime}$-particle. The $\theta^{\prime}$ and $\eta$ - $\mathrm{Fe}_{2} \mathrm{C}$ particles have, respectively, the definite lattice orientation relationships with the matrix $\alpha$, but between $\theta^{\prime}$ - and $\eta-\mathrm{Fe}_{2} \mathrm{C}$ particles any unique orientation relationship does not exist. The role of $\eta-\mathrm{Fe}_{2} \mathrm{C}$ particle is considered to provide the $\theta^{\prime}$-particle with its own surface for the nucleation.

A previous electron diffraction study ${ }^{(17)}$ has shown that synthesized $\varepsilon$-carbide of iron is stable in vacuum until $650-670 \mathrm{~K}$ and then transforms to $\chi$-carbide. Since the structures of $\varepsilon$-carbide and $\eta$ - $\mathrm{Fe}_{2} \mathrm{C}$ are very similar, the $\eta$ $\mathrm{Fe}_{2} \mathrm{C}$ particle might exist until about $650 \mathrm{~K}$. However, it disappears by the tempering between 470 and $520 \mathrm{~K}$. This difference comes from the fact that the $\eta-\mathrm{Fe}_{2} \mathrm{C}$ particle is not in vacuum but embedded in the matrix $\alpha$. Accordingly, carbon atoms in the carbide can diffuse into the matrix $\alpha$ easily, and so the $\eta-\mathrm{Fe}_{2} \mathrm{C}$ 
(a)

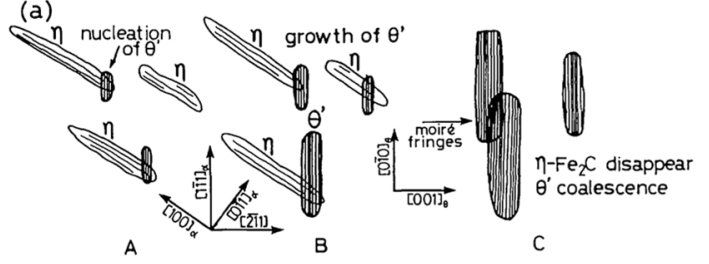

(b)

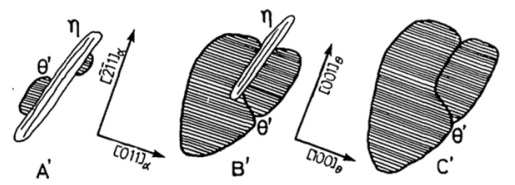

Fig. 5 Schematic illustrations showing the nucleation and growth process of $\theta^{\prime}$-particles in the transition state from the first to the early third stage of martensite tempering. The process proceeds in the order of $\mathrm{A}, \mathrm{B}$ and C. (a) Viewed along $[0 \overline{1} \overline{1}]_{\alpha} / /[\overline{1} 00]_{\theta}$. (b) Viewed along $[\overline{1} 1 \overline{1}]_{\alpha} / /[010]_{\theta}$.

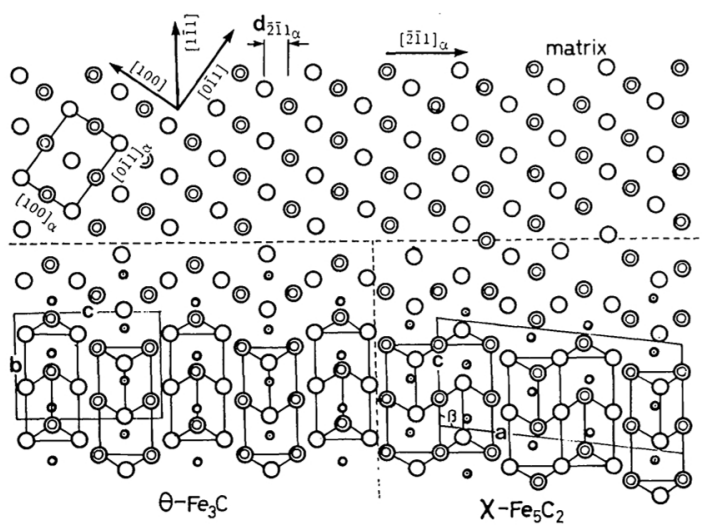

Fig. 6 Atom arrangements in $\alpha$-iron, $\theta-\mathrm{Fe}_{3} \mathrm{C}$ and $\chi-\mathrm{Fe}_{5} \mathrm{C}_{2}$ viewed respectively along the $[0 \overline{1} \overline{1}]_{\alpha},[\overline{1} 11]_{\theta}$ and $[010]_{\chi}$ directions. Large circles are iron atoms and small ones carbon atoms. The heights of atoms are distinguished by the open and double circles.

particle decomposes at the temperature much lower than $650 \mathrm{~K}$.

The $\theta-\mathrm{Fe}_{3} \mathrm{C}$ and $\chi-\mathrm{Fe}_{5} \mathrm{C}_{2}$ layers in the $\theta^{\prime}$-particle have slightly larger lattice parameters than those of the ideal ones. Such a lattice parameter anomaly has been reported by Isajchev ${ }^{(18)}$ and Murphy et al ${ }^{(19)}$. Figure 6 depicts the atom arrangements in the matrix $\alpha, \theta-\mathrm{Fe}_{3} \mathrm{C}$ and $\chi$ $\mathrm{Fe}_{5} \mathrm{C}_{2}$ viewed along the $[0 \overline{1} \overline{1}]_{\alpha},[\overline{1} 00]_{\theta}$ and $[010]_{\chi}$ directions, respectively. The structure of the matrix $\alpha$ can be regarded as the one made of stacking of $(\overline{2} \overline{1} \overline{1})_{\alpha}$ iron atom planes with spac- ing $d(\overline{2} \overline{1} 1)_{\alpha}=0.1170 \mathrm{~nm}$. On the other hand, the structure of $\theta-\mathrm{Fe}_{3} \mathrm{C}$ is made of $(001)_{\theta}$ iron atom planes with an average spacing equal to $d(006)_{\theta}=0.1124 \mathrm{~nm}$ in the case of ideal structure, while the structure of $\chi-\mathrm{Fe}_{5} \mathrm{C}_{2}$ is made of $(100)_{\chi}$ iron atom planes with an average spacing equal to $d(10,00)_{\chi}=0.1146 \mathrm{~nm}$ in the case of ideal structure. These carbide structures can be produced by the crystallographic shear $[\overline{1} 1 \overline{1}]_{\alpha},(\overline{2} \overline{1} 1)_{\alpha}$ in the matrix with appropriate rearrangements of iron atoms for the carbon atom accommodation. The lattice misfit between the matrix and the carbide is $3.9 \%$ for $\theta$ $\mathrm{Fe}_{3} \mathrm{C}$ and $2.1 \%$ for $\chi-\mathrm{Fe}_{5} \mathrm{C}_{2}$ along the $[\overline{2} \overline{1} 1]_{\alpha}$ direction in the ideal case.

Keeping Bagaryatskiy's orientation relationship the $\theta^{\prime}$-particle grows. Table 1 gives the average spacing of iron atom planes in the $\theta$ $\mathrm{Fe}_{3} \mathrm{C}$ layer $d(006)_{\theta}=0.116 \mathrm{~nm}$ and that in the $\chi$ $\mathrm{Fe}_{5} \mathrm{C}_{2} d(10,00)_{\chi}=0.116 \mathrm{~nm}$. These values are smaller only by $0.6 \%$ than the spacing $d(\overline{2} \overline{1} 1)_{\alpha}$, in contrast to the case of ideal carbide structures. Accordingly, it can be said that the lattice parameter anomaly observed in the $\theta^{\prime}$ particle comes primarily from the $(001)_{\theta}$ and $(100)_{\chi}$ iron atom planes for keeping good coherency with the $(\overline{2} \overline{1} 1)_{\alpha}$ iron atom planes in order to reduce the interfacial energy.

As was shown in the previous paper ${ }^{(9)}$, the $\theta$ particle nucleates coherently on the $(001)_{\theta}$ or $(100)_{\chi}$ surface of $\theta^{\prime}$-particle and grows at temperatures of about $650 \mathrm{~K}$ at the expense of $\theta^{\prime}$ particles. The $\theta$-particle has the ideal lattice parameters, but its orientation relationship with the matrix is not Bagaryatskiy's. The $[001]_{\theta}$ axis is rotated by about $4^{\circ}$ from the $[\overline{2} \overline{1} 1]_{\alpha}$ axis around the $[\overline{1} 1 \overline{1}]_{\alpha}$ axis. This orientation relationship can be identified with Isajchev's relationship ${ }^{(18)}: \quad(103)_{\theta} / /(011)_{\alpha}$ and $[010]_{\theta} / /[\overline{1} 1 \overline{1}]_{\alpha}$. The observed change in the orientation relationship from Bagaryatskiy's for the $\theta^{\prime}$-particle to Isajchev's for $\theta$-particle relates closely with the stacking period difference between the $\theta^{\prime}$ - and $\theta$-particles. This change may occur at temperatures above about $700 \mathrm{~K}$, since at these temperatures the matrix is recovered ${ }^{(9)}$ and so the $\theta-\mathrm{Fe}_{3} \mathrm{C}$ can grow fairly freely without keeping the coherency with the matrix.

As described in the above, the $\theta^{\prime}$-particle 
and the $\theta$-particle are different from each other in the structure, growth mechanism and the orientation relationship with the matrix. Therefore, they should be distinguished in discussing the martensite tempering.

Magnetic measurements due to Dünner and Müller ${ }^{(20)}$ and those due to Murphy et al..$^{(19)}$ showed that Curie point of the precipitated carbide in the matrix grain was higher than that of $\theta-\mathrm{Fe}_{3} \mathrm{C}$ and that with the progress of tempering it decreased gradually and became the normal value when most of $\theta$-particles were located on the grain boundary. These results can be well explained by taking into account the coexistence of $\eta-\mathrm{Fe}_{2} \mathrm{C}$ and $\theta^{\prime}$-particles at the early third stage and the transition of $\theta^{\prime}$ - to $\theta$-particle at the later third stage of martensite tempering.

\section{Acknowledgment}

This study was partly supported by the Grant-in-Aid for the Fundamental Researches from the Ministry of Education, Science and Calture, Japan.

\section{REFERENCES}

(1) Y. Hirotsu, S. Nagakura and S. Oketani: Proc. Intern. Conf. on Sci. Technol. Iron and Steel (Suppl. Trans. ISIJ, vol. 11), (1971), 1140.

(2) Y. Hirotsu and S. Nagakura: Acta Metall., 20 (1972), 645.

(3) Y. Hirotsu and S. Nagakura: Trans. JIM, 15 (1974), 129.
(4) Y. Hirotsu, Y. Itakura, K.-C. Su and S. Nagakura: Trans. JIM, 17 (1974), 503.

(5) K. Shimizu and H. Okamoto: Trans. JIM, 15 (1974), 193.

(6) Y. Tanaka and K. Shimizu: Trans. JIM, 22 (1981), 779.

(7) S. Nagakura, T. Suzuki and M. Kusunoki: Trans. JIM, 22 (1981), 699.

(8) S. Nagakura, Y. Hirotsu, M. Kusunoki, T. Suzuki and Y. Nakamura: Metall. Trans. A, 14A (1982), 1025.

(9) Y. Nakamura, T. Mikami and S. Nagakura: Trans. JIM, 26 (1985), 876.

(10) Y. Nakamura and S. Nagakura: Proc. 7th Intern. Conf. on High Voltage Electron Microscopy (U. C. Berkely, Cal. Ed. R. M. Fisher, R. Gronsky and K. H. Westmacott), (1983), 221.

(11) Yu. A. Bagaryatskiy: Dokl. Akad. Nauk SSSR, 73 (1950), 73.

(12) E. J. Fasiska and G. A. Jeffrey: Acta Crystallog., 19 (1965), 436.

(13) K. H. Jack and S. Wild: Nature, 212 (1960), 248.

(14) B. G. Hyde: AIP Conf. Proc. No. 73 (Modulated Structures-1979, Ed. J. M. Cowley, J. B. Cohen, M. B. Salomon and B. J. Wuensch, Am. Inst. Phys.), (1979), 80.

(15) Y. Ohmori and S. Sugisawa: Trans. JIM, 12 (1971), 176.

(16) Y. Imai, T. Ogura and A. Onoue: Tetsu-to-Hagané, 58 (1971), 726.

(17) S. Nagakura: J. Phys. Soc. Jpn., 14 (1954), 186.

(18) I. V. Isajchev: Zh. Tekhnol. Fiz., 17 (1947), 839.

(19) S. Murphy, J. A. Whiteman and J. H. Woodhead: The Mechanism of Phase Transformation in Crystalline Solids, Institute of Metals, No. 33, (1967), p. 72.

(20) Ph. Dünner and S. Müller: Acta Metall., 13 (1963), 23. 